\title{
GOLPE OU REVOLUÇ̃̃O? UM JOGO DISCURSIVO NA MÍDIA
}

FRANCIS LAMPOGLIA; JONATHAN RAPHAEL BERTASSI DA SILVA;
GUSTAVO GRANDINI BASTOS; LUCÍLIA MARIA ABRAHÃO E SOUSA

\author{
Faculdade de Filosofia, Ciências e Letras de Ribeirão Preto \\ Universidade de São Paulo
}

Av. Bandeirantes, 3900 - 14040-901 - Monte Alegre - Ribeirão Preto - SP - Brasil

francidusp@hotmail.com ; gugrandini@uol.com.br ;

cid_sem_registrodyahoo.com.br ; luciliamsrauol.com.br

\begin{abstract}
Resumo. Pretendemos com este artigo interpretar os efeitos de sentido que se inscrevem ao enunciar sobre a ditadura militar brasileira (1964-1985), partindo das nomeações que o período recebeu a partir de diferentes posições que o sujeito ocupa. Para tanto, utilizamos um editorial da Folha de S. Paulo que batizou os anos de chumbo como "ditabranda", as imagens de um blog acerca da polêmica placa em um memorial da Universidade de São Paulo (USP) e manchetes inscritas nos jornais dos anos sessenta que anunciaram a tomada do poder pelos militares, para a realização de nossas análises e considerações, fazemos uso da Análise do Discurso de filiação francesa.
\end{abstract}

Palavras-chave: Ditadura Militar Brasileira; memória discursiva; esquecimentos.

\begin{abstract}
We intend with this paper to interpret the effects of sense in stating that fall on the Brazilian military dictatorship (1964-1985), from the nominations received to the period from different positions that the subject occupies. We used an editorial in the Folha de S. Paulo baptized the years that lead to "ditabranda", images of a blog about the controversial card in memorial of Universidade de São Paulo (USP) and headlines in the newspapers entered the sixties who announced the seizure of power by the military to conduct our analyzes and considerations we make use of French Discourse Analysis.
\end{abstract}

Keywords: Brazilian Military Dictatorship; discursive memory; discursive forgetfulness.

\section{Introdução}

Neste trabalho, buscamos compreender os efeitos de sentido nas denominações que a ditadura militar brasileira recebeu, seja no momento em que o golpe dos militares foi deflagrado em 1964, seja no modo como o período é lembrado posteriormente pelo governo ou pela imprensa majoritária - representada em nossas análises, sobretudo, pelo jornal Folha de S. Paulo. Para realizar as análises de recortes que chamam o golpe/revolução de diferentes maneiras, entendemos como adequado o referencial teórico da Análise do Discurso (AD) francesa, já que seu objeto de análise - o discurso - é entendido justamente como efeito de sentido entre interlocutores (PÊCHEUX, 1997) e refuta de modo categórico a existência de pretensos sentidos "legítimos" ao que circula em qualquer meio de comunicação, inclusive os atrelados à memória oficial do governo. 
Por se opor à ciência positivista e conteudista, a $\mathrm{AD}$ entende que há sentidos que são cristalizados historicamente pela ideologia e se tornam transparentes aos sujeitos que os tomam para fazer falar seus dizeres (a partir de uma formação discursiva determinada, também, pela ideologia), mas jamais relega aos outros sentidos possíveis um espaço minoritário. Pelo contrário: interessa para a $\mathrm{AD}$ investigar as condições de produção e compreender justamente porque certas regiões de sentido surgem como marginais, interditadas, enquanto outras instalam sentidos de legitimidade. Uma vez que a ditadura militar acabou há quase trinta anos, notamos que os recortes da memória aos quais o sujeito recorre para falar desse período nebuloso de nossa história estão longe do consenso: as palavras "golpe" e "revolução" instalam efeitos de sentido bastante diversos de apoio e/ou confronto com relação à tomada do poder pelos militares, as denominações são conflituosas tanto nas vozes do governo quanto na mídia. Há até quem diga que o que tivemos no Brasil não passa de uma "ditabranda", neologismo de forte apelo político colocado no editorial de um jornal, a Folha de São Paulo, que com frequência se diz "imparcial" - algo que, como veremos, para a AD é impossível, quer queira reconhecer o sujeito sua condição de interpelado pela ideologia, quer não. Como a polêmica permanece atual, gerou um embate envolvendo governo, mídia e população e enlaça diretamente questões acerca da imbricação entre linguagem e memória discursiva, julgamos pertinente levar à tona nossas ponderações, recorrendo ao corpus do momento do golpe/revolução e de fatos mais recentes, os quais - veremos - remetem à formações discursivas em contraste e mantém regularidades quanto à "escolha" das palavras para falar da ditadura militar.

\section{O discurso de Michel Pêcheux: sentidos em trânsito}

A Análise do Discurso, que ora empregamos para nos ajudar a compreender teoricamente os efeitos de sentido acerca da polêmica do golpe/revolução, foi desenvolvida em final dos anos sessenta por Michel Pêcheux, com base em outros teóricos em voga na época como Louis Althusser e Jacques Lacan. Com essas bases, Pêcheux - filósofo de formação - levou postulados do materialismo histórico da teoria marxista e da psicanálise para suas inquietações relacionadas à Linguística. Assim, Pêcheux fala de um sujeito necessariamente afetado pela ideologia e pelo inconsciente, ou seja, não é dono de seus sentidos, não é senhor de suas palavras, tampouco controla o processo de significação da linguagem que joga com o social e está sempre em movimento.

Apesar de não controlar "seus" sentidos, todavia, o sujeito imagina que pode fazêlo. Os sujeitos são inconscientes do que a ideologia determina e da posição que, por meio dela, ocupam em uma formação discursiva (FD) - ideologia e inconsciente atuam em conjunto nesse processo. Daí vem a ilusão do sujeito de ser uno, cartesiano, ao invés de atravessado pelo desejo e pelos jogos do poder, ambos materializados na linguagem. Dessa maneira, a AD não se propõe a investigar o "indivíduo", noção da qual se distancia; ou seja, o sujeito não é quantificável, categorizante ou mensurável como é o indivíduo. $\mathrm{O}$ indivíduo não se apropria da linguagem; uma vez que ela é social, sua apropriação também o é. É a questão do assujeitamento, conforme palavras do próprio Pêcheux 
(2011), em que o sujeito deixa de ser visto como o "eu-consciência", mestre dos sentidos e passa a ser encarado como assujeitado ao discurso.

O sujeito então (re)produz as palavras partindo da ideia de ser fonte de seu dizer quando, na verdade, retoma sentidos preexistentes. Embora perceba seus dizeres como transparentes, aceitando as palavras e "seus" significados como evidentes, o sujeito não controla o que diz, nem tampouco tem acesso ao modo como os sentidos se constituem nele, pois ' $[\ldots .$.$] o sujeito se 'esquece' das determinações que o colocaram no lugar que ele$ ocupa - entendemos que, sendo 'sempre-já' sujeito, ele 'sempre-já' se esqueceu das determinações que o constituem como tal” (PÊCHEUX, 1997, p. 170). A voz do sujeito, assim sendo, revela tanto seu lugar social quanto expressa também uma série de outras vozes que ecoam ali, constitutivas desses dizeres. Tal retomada das outras vozes, bem como a interpelação ideológica, que cristaliza os sentidos para o sujeito, nem sempre é pacífica, já que a língua é tendente ao equívoco e à ideologia, um ritual com falhas.

A ilusão de ser fonte dos sentidos e que os seus dizeres não podem ser outros é inscrita na $\mathrm{AD}$ pela noção, formulada por Pêcheux (op. cit.), dos esquecimentos que constituem o sujeito. O esquecimento $\mathrm{n}^{\circ} 1$, que Pêcheux chama de esquecimento ideológico, é constitutivo da subjetividade na língua, de ordem inconsciente e inacessível ao sujeito. Diz respeito ao modo pelo qual a ideologia nos afeta, gerando a ilusão que temos "[...] de ser a origem do que dizemos, quando, na realidade, retomamos sentidos preexistentes" (ORLANDI, 2005, p. 35). Por meio do esquecimento $\mathrm{n}^{\mathrm{o}} 2$, dito enunciativo, o sujeito tem a impressão de que seus dizeres só poderiam ser formulados de uma forma, causando a ilusão referencial que nos faz crer que a relação entre palavras e pensamentos é direta, esquecendo que o dizer sempre pode ser outro, visto que ao longo dos nossos dizeres vão se formando famílias parafrásticas do que poderíamos ter dito, mas não dissemos. Esses conceitos são imperativos para que possamos compreender os efeitos de sentido acerca do golpe/revolução e toda a polêmica acerca disso: afinal, nesse conceito verificamos que o sujeito se esquece que pode escolher o que diz, sendo esse esquecimento condição para que o sujeito possa enunciar. De qualquer maneira, a formulação das frases sobre a ditadura militar e referências ao período vai implicar no uso deste ou daquele termo e, portanto, inevitavelmente se filiará ideologicamente a regiões de sentido que falam de certa maneira da ditadura, em detrimento de outras possíveis.

A tensão entre palavras, que revela camadas mais profundas de filiação das FDs das quais partem os enunciados da mídia, do governo ou de manifestantes, nos remete ao caráter polissêmico do discurso, das múltiplas formulações possíveis para falar da ditadura, mas que por trás de diferenças sutis guardam, como notamos nas análises, dizeres heterogêneos, nem sempre de modo marcado. Elaborado por Jacqueline AuthierRevuz a partir dos postulados bakhtinianos acerca do dialogismo, a heterogeneidade discursiva refere-se ao conjunto de vozes que compõem o dizer, podendo ser distinguida entre mostrada e constitutiva. Na heterogeneidade mostrada é possível identificar a presença do outro no discurso, delimitando o que se considera como exterior do interior do discurso. Conforme Authier-Revuz conceitua que

[...] localizar um ponto de heterogeneidade é circunscrever este ponto, ou seja, opô-lo por diferença do resto da cadeia, à homogeneidade ou à unicidade da língua, do discurso, do sentido etc.; corpo estranho delimitado, o fragmento marcado recebe nitidamente através das glosas 
de correção, reserva, hesitação... um caráter de particularidade acidental, de defeito local. Ao mesmo tempo, remete a um alhures, a um exterior explicitamente especificado ou dado a especificar, determina automaticamente pela diferença um interior, aquele do discurso; ou seja, a designação de um exterior específico é, através de cada marca de distância, uma operação de constituição de identidade para o discurso. (AUTHIER-REVUZ, 1990, p. 31)

A heterogeneidade mostrada, então, diferencia o que se imagina pertencente ao discurso alheio do que é "interior", conferindo a este uma identidade. Este tipo de heterogeneidade pode ainda dividir-se em marcada e não-marcada. Enquanto a marcada refere-se ao discurso do outro identificável através de vestígios linguísticos, tais como o uso de aspas, dois pontos, travessão, dentre outros, "dando forma ao discurso - pela forma, pelo contorno, pelas bordas, pelos limites que elas traçam - e dando forma ao sujeito enunciador - pela posição e atividade metalinguística que encenam" (AUTHIERREVUZ, 1990, p. 33), a heterogeneidade mostrada não marcada não possui pontuações específicas da fala do outro no texto, mas ao tomar contato com o discurso, é possível que a voz do outro seja escutada. Segundo a autora, “[...] as formas não marcadas da heterogeneidade mostrada - discurso indireto livre, ironia... de um lado, metáforas, jogos de palavras... de outro lado - representam, [...] a incerteza que caracteriza a referência ao outro, uma outra forma de negociação com a heterogeneidade constitutiva" (AUTHIERREVUZ, 1990, p. 34).

$\mathrm{Na}$ heterogeneidade constitutiva, o outro se encontra diluído no discurso, de maneira que não é possível identificar as vozes que constituem o seu dizer. Resgatando duas características do dialogismo formulado por Mikhail Bakhtin, a heterogeneidade constitutiva trata da natureza de todo discurso, que é construir-se em meio a outros discursos e modelada conforme o destinatário, sem que as marcas do outro possam ser identificadas explicitamente na superfície do discurso. Para a autora, "esse duplo dialogismo - que participa do que chamo de heterogeneidade constitutiva de todo discurso - escapa larga e inevitavelmente ao enunciador e não se manifesta no fio do discurso por marcas linguísticas" (AUTHIER-REVUZ, 1999, p. 10). Nessa abordagem conceitual de heterogeneidade, pressupõe-se o discurso como produto do interdiscurso dizeres já proferidos que fundamentam o discurso - e que o sujeito, atingido pelo inconsciente, ignora que seu dizer é construído por esses já-ditos e imagina-se fonte de seu discurso. Sobre isso, Pêcheux considera que

[...] o próprio de toda formação discursiva é dissimular, na transparência do sentido que nela se forma, a objetividade material contraditória do interdiscurso, que determina essa formação discursiva como tal, objetividade material essa que reside no fato de que "algo fala" (ça parle) sempre "antes, em outro lugar e independentemente". (PÊCHEUX, 1997, p. 162)

O conceito de Formação Discursiva (doravante FD) é compreendido por vários autores da Análise do Discurso de filiação francesa como delicado e polêmico (ORLANDI, 2005; BARONAS, 2011; INDURSKY, 2011), mas ao mesmo tempo, de extrema importância para a teoria na qual trabalhamos (ORLANDI, 2005), ou melhor, de uma forma geral, para os estudos da linguagem (INDURSKY, op. cit.). Conceito este, que na França, deixou de ser amplamente discutido desde o começo da década de 1980, paralelamente, no Brasil, essa noção persiste em ser amplamente trabalhada e (re)pensada 
por pesquisadores (BARONAS, op. cit.). Nas colocações de Baronas (2004), propõe-se uma abordagem do conceito de FD como "uma paternidade partilhada" (BARONAS, 2011, p. 194) entre Michel Pêcheux e Michel Foucault. De acordo com o autor, o conceito de FD aparece pela primeira vez em A Arqueologia do Saber, de Foucault, no ano de 1968, enquanto em Pêcheux é mencionado no texto A Semântica e o corte Saussuriano: língua, linguagem e discurso de 1971, no entanto, ele destaca que Pêcheux no ano de 1968, com o texto Lexis et metalexis: les problemes des determinants, escrito em conjunto com C. Fuchs, pensou e refletiu acerca do conceito de FD, mas na ocasião não nomeouo. Por conta disso, se pode "asseverar que, pelo menos no seu processo de gestação, esse conceito não veio da Arqueologia do Saber de Michel Foucault, cuja primeira publicação data de 1969" (BARONAS, op. cit., p. 199).

A FD sempre foi um conceito caro para Pêcheux (INDURSKY, 2007), sendo que ideologia e sujeito são seus princípios organizadores. Em nosso texto, trabalharemos com a perspectiva do conceito de FD em Michel Pêcheux, dessa forma, compreendemos que "uma mesma palavra, uma mesma expressão, uma mesma proposição podem receber sentidos diferentes - todos igualmente 'evidentes' - conforme se refiram a esta ou aquela formação discursiva” (PÊCHEUX, 1997, p. 161). Conforme apresentado por Pêcheux, o conceito de FD é entendido como

[...] aquilo que, numa formação ideológica dada, isto é, a partir de uma posição dada numa conjuntura dada, determinada pelo estado da luta de classes, determina o que pode e deve ser dito (articulado sob a forma de uma arenga, de um sermão, de um panfleto, de uma exposição, de um programa etc.). (PÊCHEUX, op. cit., p. 160)

Na busca por assegurar a certeza é que o sujeito tenta, desesperadamente, garantir à segurança no campo da linguagem, desejando, incessantemente, colar às palavras as coisas (LAGAZZI-RODRIGUES; BRITO, 2001), mas o que se entende é que o significado das palavras está fortemente vinculado à questão da FD que são produzidas, o "sentido se torna um efeito sobre um sujeito ativo, e não uma propriedade estável" (BARONAS, 2011, p. 200). Dessa forma, o sentido fixo é algo da ordem do inexistente, do mítico.

Filiado a uma determinada FD, o sujeito, nas perspectivas da AD, assume uma dada posição e dela enuncia, sendo essa tomada de posição necessária para a produção de sentidos, assim "é a posição que deve e pode ocupar todo indivíduo para ser sujeito do que diz. O modo como o sujeito ocupa seu lugar, enquanto posição, não lhe é acessível, ele não tem acesso direto à exterioridade (interdiscurso) que o constitui" (ORLANDI, 2005, p. 49).

Desconhecendo o interdiscurso que o constrói, o sujeito imagina-se livre para escolher a formação discursiva em que se filia. Entretanto, "o interdiscurso determina a formação discursiva com a qual o sujeito, em seu discurso, se identifica, sendo que o sujeito sofre cegamente essa determinação, isto é, ele realiza seus efeitos 'em plena liberdade" (PÊCHEUX, 1997, p. 215). Com isto, um sujeito que ocupa uma dada posição e inserido em uma formação discursiva, molda seu discurso e seleciona suas palavras visando à circulação de determinados sentidos e o silenciamento de tantos outros. Tal exercício deixa marcas no discurso, possibilitando que o analista identifique, através dos 
vestígios discursivos, a postura do sujeito em relação a um dado acontecimento, e é isso que veremos a seguir.

\section{Análises em Três Tempos: discursos sobre a Ditadura Militar Brasileira}

Os diferentes posicionamentos em relação ao regime de 1964 podem ser detectados desde a época da eclosão do golpe até os dias de hoje, através dos discursos materializados em jornais, revistas, vídeos e com o advento da internet, em blogs, sites, dentre outros ${ }^{1}$. Mesmo em conversas informais, como num ponto de ônibus, no bar da esquina, na padaria, ou formais, como numa discussão no Congresso Nacional, numa aula universitária, dentre outros, esse tema frequentemente aparece e com ele, os posicionamentos de cada sujeito envolvido no discurso. Neste artigo, iniciaremos nossas análises por três recortes de jornais de 1966, anos iniciais da ditadura militar, sendo dois recortes oriundos da Folha de S. Paulo e três do jornal Última Hora. Feito isso, passaremos para análise de referências mais recentes ao golpe/revolução, em uma placa do governo e em um editorial da Folha.

O primeiro recorte selecionado trata-se da manchete de capa da Folha de S. Paulo que traz os seguintes dizeres em letras grandes e destacadas "NO BRASIL NÃO HÁ DITADURA", precedida dos dizeres acima, com letras menores, que explicam "Castelo responde às críticas do Senado dos EUA" (FOLHA, 23/05/1966, p. 1). Tal manchete, publicada em 23 de maio de 1966, não possui marcas que distinguem a fala do então presidente Castelo Branco da fala do jornal, incorporando, assim, o dito presidencial a seus próprios dizeres. Ao não distinguir a fala do presidente com a sua, o jornalista assume para si o discurso de Castelo, o que indica sentidos de alinhamento entre o posicionamento do jornal com o do governo. Abaixo das letras garrafais, no lado esquerdo do jornal, há o título "Você também votará" e mais abaixo, a chamada da notícia "Participação do operário no capital" que, aliados ao dizer da manchete, instiga sentidos de democracia, de que o país não se encontra sob um regime autoritário, mas participativo.

Já na primeira página do jornal Última Hora publicado no mesmo dia, na edição matutina (figura 1), verifica-se que o dizer em destaque "Não há presos políticos" encontra-se entre aspas, marcando o distanciamento entre a fala do jornal e a do presidente, indicando o dizer de cada sujeito e delimitando o que se considera exterior do interior do discurso. Para Authier-Revuz (1990),

[...] a zona de 'contato' entre exterior(es) e interior que mostra as marcas de distância num discurso é profundamente reveladora deste discurso, de um lado pelos pontos escolhidos para colocar explicitamente fronteiras, limites, demarcações [...] - de outro lado, pelo tipo de relação que aí se joga com o outro, relação explicitamente pelas glosas ou interpretável pelo contexto. (AUTHIER-REVUZ, 1990, p. 31)

\footnotetext{
${ }^{1}$ Sobre os diferentes posicionamentos em relação à ditadura militar nos jornais e nas hemerotecas que as abrigam, ver Lampoglia (2012).
} 
Nota-se, então, que diferentemente da Folha de S. Paulo, o sujeito-jornalista do Última Hora não toma para si o discurso de Castelo, mas o coloca em posição de estranhamento, já que a manchete em destaque é precedida pelos dizeres "Causou espanto a afirmação de Castelo". A palavra "espanto" instiga sentidos de contrariedade em relação à fala de Castelo, marcando que a posição do sujeito-jornalista não compactua com a do sujeito-presidente.

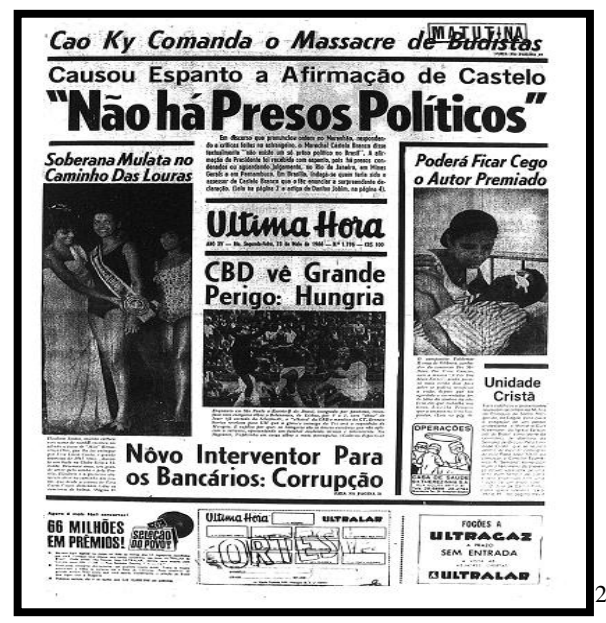

llustração 1. Jornal Última Hora de 23 mai. 1966.

$\mathrm{Na}$ edição vespertina do jornal (figura 2), flagramos um dizer mais coloquial e irônico em relação à edição matutina:

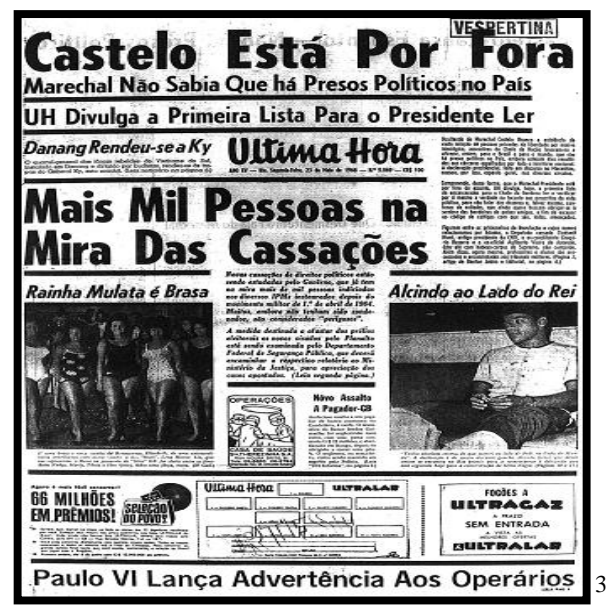

Ilustração 2. Jornal Última Hora, de 23 mai. 1966.

\footnotetext{
2 ÚLTIMA Hora, p. 1, 23 mai. 1966, edição matutina. Disponível em http://www.arquivoestado.sp.gov.br/uhdigital/imagens/icone.jpg; acesso em jan. 2014.

3 ÚlTIMA Hora, p. 1, 23 mai. 1966, edição vespertina. Disponível em http://www.arquivoestado.sp.gov.br/uhdigital/imagens/icone.jpg; acesso em jan. 2014.
} 
Com a manchete "Castelo está por fora", seguido dos subtítulos "Marechal não sabia que há presos políticos no país" e "UH divulga a primeira lista para o presidente ler" nota-se que os dizeres não só apontam sentidos da existência da ditadura no Brasil como também sugere, ironicamente, que o presidente é mal informado sobre seu próprio país. Tendo por pressuposto que "[...] na ironia expressa-se com as palavras um conceito mas se subentende (sem expressá-lo por palavras) um outro, contrário" (PROPP, 1992, p. 125), essa figura de linguagem pode ser identificada no trecho devido ao fato de que, ocupando a posição de presidente da república, Castelo deve saber o que se passa no país, não sendo, portanto, dependente das notícias de um jornal para saber o que acontece no Brasil, já que possui assessores para isso. O efeito de ironia é inscrito pelo tom quase coloquial no emprego da expressão "por fora", o que junto com a denominação que deram ao presidente (simplesmente com a palavra "Castelo") sugere tanto a memória dos monarcas distantes do povo, quanto de um fechamento em si mesmo numa edificação que remonta à Idade Média, ao que já é ultrapassado. Tal funcionamento faz falar o sentido de desconhecimento da realidade nacional e a alienação diante do que acontece com os brasileiros. Dessa forma, é possível perceber sentidos de que o presidente mentiu ao responder ao senado americano de que aqui vigorava um regime ditatorial. Sentidos de governo autoritário também podem ser detectados em outro título abaixo, que afirma "Mais de mil pessoas na mira das cassações", indicando rastros de uma FD contrária do periódico ao regime da época. Nota-se também a ausência de aspas nas manchetes, marcando que o jornal assume a fala quando se trata de afirmar a existência de presos políticos, mas distancia-se de assumir uma posição de denúncia em relação à negativa do presidente sobre a prisão política. Aí sim temos as aspas como marca de heterogeneidade mostrada marcada, o que indica, mais uma vez, a filiação do jornal à FD hostil ao golpe militar.

As marcas que apontam para o posicionamento do jornal também podem ser detectadas na capa do jornal Folha de S. Paulo do dia 22 de setembro de 1966, que tem como manchete "CASTELO: REPRESSÃO SEM EXCESSOS" (FOLHA, 22/09/1966, p. 1). Os dois pontos indicam que o dizer partiu do presidente, mas não necessariamente com essas palavras, já que não está entre aspas. Assim como está posta, a manchete aponta tanto para um desejo do sujeito-presidente (ele quer que a repressão seja sem excessos) como uma constatação do mesmo (a repressão não teve excessos), pois a ausência do verbo que indique o tempo dá margem a esses efeitos de sentido. Nota-se também que a palavra utilizada foi "excessos" e não "violência", remetendo a sentidos de que a violência pode ocorrer, desde que não haja excessos. Esta palavra em discurso pelo jornal também aponta para sentidos imprecisos, até mesmo subjetivos, já que o sentido de excesso varia entre sujeitos. O que é excesso para um, pode não ser para outro, e assim sucessivamente, pois não é estipulado um limite "tolerável" de repressão e, que acima disso, é excedente. Observa-se também que a marca "violência" foi silenciada da capa, mas mesmo assim os sentidos que remontam a ela continuam presentes. Se é certo que o silenciamento de um significante impede que certos sentidos circulem, também é possível dizer que isso não significa que a violência nunca tenha existido.

Já o jornal Última Hora publica a seguinte capa na edição vespertina de 22 de setembro de 1966 (figura 3): 


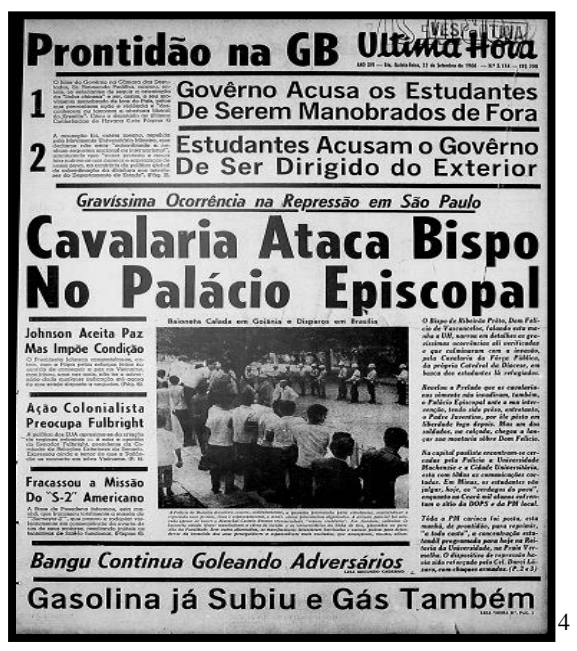

Ilustração 3 - Jornal Última Hora de 22 set. 1966.

Ao destacar que houve "Gravíssima ocorrência na repressão em São Paulo: cavalaria ataca bispo no Palácio Episcopal", o jornal denuncia justamente o contrário do que diz Castelo na capa da Folha. Aqui, nota-se que a palavra "gravíssima" marca sentidos de excessos que a repressão estaria cometendo, entrando em conflito com os dizeres da Folha, revelando que os dois jornais se filiam a formações discursivas distintas. Nesta manchete, percebemos um conflito entre dois aparelhos ideológicos, sendo a cavalaria representando os Aparelhos Repressivos do Estado (ARE) e o bispo, os Aparelhos ideológicos de Estado (AIE), ou seja, as forças armadas contra a Igreja católica. Entretanto, o número de representantes de cada aparelho envolvidos nesse conflito em particular é desigual, já que a cavalaria implica num grupo de policiais montados a cavalo e o bispo é apenas um, sem nenhuma montaria. Percebe-se, então, que se forma uma imagem violenta, desigual e covarde por parte dos militares, que atacam em grupo um sujeito, que não é qualquer um, mas que ocupa a posição de bispo, representante da Igreja cujos adeptos são maioria no Brasil. Nota-se também que a palavra "atacar" remete a sentidos de agressão física que se aproxima do animalesco (o que é reforçado pelo uso da palavra "cavalaria"), agressão essa direcionada a uma só pessoa, em propriedade episcopal. Observa-se, então, que a Igreja é atingida duas vezes, primeiro por atacar seu representante e segundo por macular um solo sagrado.

Com isso, verificamos que, sob um mesmo tema, os jornais constroem seus dizeres conforme a formação discursiva na qual se filiam, fazendo circular determinados sentidos e silenciando outros. Embora houvesse repressão e censura durante o regime militar, que visavam impedir que o sujeito adentrasse em certas regiões de sentido, é possível identificar, através da seleção de palavras e da forma de construção do discurso, o posicionamento dos jornais em relação à ditadura. Entretanto, os posicionamentos assumidos em relação ao governo militar não se limitaram a época de sua vigência, mas repercutem até hoje, 27 anos depois de seu término, como veremos a seguir.

\footnotetext{
4 ÚltiMA Hora, p. 1, 22 set. 1966, edição vespertina. Disponível em http://www.arquivoestado.sp.gov.br/uhdigital/imagens/icone.jpg; acesso em jan. 2014.
} 


\section{Golpe, Revolução ou Ditabranda?}

"Vejo tanta notícia desagradável sobre a Irlanda, o Vietnã, os índios americanos, e, no que diz respeito ao Brasil, está tudo em paz." : são emblemáticas as palavras do general Emílio Garrastazu Médici, dito "presidente" do Brasil no início dos anos setenta, que remetem diretamente ao mito do "homem cordial" tipicamente brasileiro. Compreendido no âmbito do discurso, tal recorte na memória discursiva, que militares como Médici fazem de uma suposta bonança característica do Brasil pela falta de violência e protestos, encontra forte amparo nos silenciamentos que a mídia dominante promove desde o período da ditadura acerca dos presos, torturados e desaparecidos políticos. Vimos acima algumas análises que evidenciam essas omissões criminosas e, igualmente, os furos que a imprensa de resistência aos militares encontrava para deixar fluir sentidos de denúncia sobre os crimes perpetrados pelo Estado.

Nos recortes abaixo, flagraremos como os silenciamentos da FD favorável aos militares, na mídia e na memória oficial do próprio Estado, continuam presente em suas regularidades discursivas com plena força - mesmo décadas depois do fim do retorno da democracia, em 1985. No tocante à mídia, cabe destacar o editorial intitulado "Limites a Chávez" publicado pelo jornal Folha de S. Paulo em 17 de fevereiro de $2009^{6}$. Na ocasião, ao buscar tecer críticas ao governo do presidente venezuelano e comparando-o a uma ditadura, Folha se referiu à ditadura brasileira com o termo "ditabranda" ("[...] se as chamadas 'ditabrandas' - caso do Brasil entre 1964 e 1985[...]"). Discursivamente, tanto o uso das aspas quanto o uso deste termo em vez de outros para designar o período tem extrema importância e revelam a FD à qual a Folha se ampara para circular sentidos sobre a memória do que representou a ditadura e de como ela deve ser lembrada quase vinte e cinco anos depois de seu término. Sobre as aspas, que implicam em heterogeneidade marcada, notamos a antecipação imaginária do sujeito-editor ao se eximir de "responsabilidades" sobre o uso do significante, o que é reforçado pela expressão "se as chamadas", que remete marcadamente ao dizer de um outro, o qual o jornal Folha não revela, mas corrobora seus dizeres. Já no uso das aspas, portanto, o sujeito antecipa a força do termo e o potencial conflito com outras FDs. O faz, todavia, sob uma máscara de pretensa neutralidade e obviedade, o que é característico da grande mídia, como lembra Romão (2005, p. 240):

Esse cruzamento de vozes é amarrado de maneira heterogênea, mas, ao mesmo tempo, tenta parecer um produto final e chegar ao leitor como efeito de unidade, neutralidade, exatidão e objetividade. Efeitos esses pretendidos e, não raro, vendidos como atributos diferenciais por certos órgãos de imprensa.

Com o conceito dos esquecimentos de Pêcheux, principalmente o segundo (enunciativo), notamos a intensidade da palavra na FD que permeia o editorial: enquanto vários significantes poderiam ocupar o mesmo lugar na frase para se referir ao período (ditadura, golpe militar, revolução, etc.), a Folha usou justamente o termo "ditabranda",

5 Citação disponível em http://parabolicadoblum.blogspot.com/2008/12/64-frases-duplipensadas-doregime.html; acesso em fev. 2014.

6 O editorial e as cartas dos leitores sobre o mesmo se encontram disponíveis no endereço http://www.nucleodenoticias.com.br/2009/02/27/leia-na-integra-o-polemico-editorial-da-folha-de-s-

paulo; acesso em fev. 2014. 
deixando implícito ao mesmo tempo que o governo Chávez é o oposto disso (uma "ditadura" de fato) e relativiza a violência ocorrida no período. No entanto, o silêncio da historicidade e da memória que eivam desse significante - memória esta que o sujeitoeditor reconhece pelo uso das aspas - não é evidenciada ao sujeito-leitor.

Trata-se, na verdade, de uma expressão utilizada em 1983 pelo então ditador chileno Augusto Pinochet, ao responder críticas sobre seu governo. A Folha, desta forma, se filiou à FD alinhada à relativização da tortura e das mortes que aparece como regularidade na voz dos próprios déspotas à frente do poder na ocasião dos diversos golpes militares da América Latina. Tanto é que o Brasil não é a única "ditabranda" para a Folha, já que a palavra é usada no plural no editorial, deixando subentendido que outras ditaduras latino-americanas também foram "brandas". Por aí, instala-se um sentido de que a ditadura brasileira não foi mais "branda" do que as vizinhas e contemporâneas, mas se estabelece uma comparação direta no editorial com o modo de governar que FD que o sujeito-editor entende como oposta, no caso, o do presidente Chávez. Essa leitura do termo usado pelo jornal a partir de sua historicidade, contudo, é vetada na Folha, na medida em que o editorial não se preocupa em contextualizar. Bem ao contrário, ainda vende uma suposta "imparcialidade" de si (e, por conseguinte, da FD que se ampara) e sustenta tal apagamento como diferencial positivo para almejar mais alcance mercadológico, como se fosse possível no discurso de qualquer jornal não existir interpelação ideológica, ao passo que a FD contrária, como a do governo venezuelano e outros diferentes da "ditabranda", são apontados como negativos não só pelo seu viés ideológico adverso, mas simplesmente por ter um viés ideológico, visto que a Folha projeta ao leitor a possibilidade de estar "fora" da ideologia.

Não é só na imprensa que a polêmica sobre as denominações da ditadura militar ainda é contundente e revela a atualização/manutenção dos dizeres sobre o período nos dias atuais. O recorte abaixo (figura 4) foi retirado do blog Vi o mundo: o que você não vê na política ${ }^{7}$ apresentando fotos da polêmica placa que anunciava a construção do Monumento em Homenagem a Mortos e Cassados na Revolução de 1964, espaço destinado para lembrar os perseguidos no período da Ditadura Militar brasileiro. O blog apresenta a foto (antes e depois das intervenções escritas na placa), a questão foi amplamente discutida e veiculada em espaços midiáticos importantes como em uma matéria, mais uma vez, na Folha de S. Paulo ${ }^{8}$. Destacamos que a foto usada na reportagem da Folha foi feita por um fotografo profissional e obteve grande destaque e circulação, nela só temos a escrita da palavra "golpe", enquanto a imagem aqui utilizada faz uso da fotografia de um blog já citado, nela temos outras duas marcas ali presentes, inscritas, posteriormente a foto tirada pela Folha, por uma aluna da Universidade de São Paulo (USP) em sinal de protesto. Optamos pelo trabalho apenas com a palavra "golpe", pois foi essa que obteve grande circulação e debate nos espaços midiáticos, além disso, as outras não circularam tanto nos dizeres de diferentes espaços.

\footnotetext{
${ }^{7}$ Postagem do blog Vi o mundo: o que você não vê na política, de postagem do dia 04 de outubro de 2010, intitulada "Aluna da USP: Escrevi ditadura e massacre; placa me agrediu muito". Disponível em http://www.viomundo.com.br/denuncias/aluna-da-usp-escrevi-ditadura-e-massacre-placa-me-agrediuprofundamente.html; acesso em nov. 2014.

${ }^{8}$ Matéria do Jornal Folha de São Paulo de 04 de Outubro de 2010, intitulada: "Placa na USP chama golpe militar de 'revolução de 1964"'. Disponível em: <http://www1.folha.uol.com.br/poder/985149-placa-nausp-chama-golpe-militar-de-revolucao-de-1964.shtml>. Acesso em: 28 nov. 2014.
} 
A placa apresenta muitas marcas que nos chamam a atenção, mas duas merecem destaque em nosso gesto de análise: i) o uso da palavra "revolução" para indicar a tomada de poder pelos militares, no ano de 1964, em uma placa que indica a construção de um memorial para as vítimas do período de duração desse regime, sendo que ela se apresenta legitimada pelas vozes de órgãos oficiais, como a Secretaria Especial dos Direitos Humanos e a Petrobras; ii) o gesto de ruptura, rabisco, risco com esse dizer na própria placa. No qual temos o apagamento e a quebra de um dizer instituído dentro do espaço de dizer oficial.

Iniciamos o trajeto de análise com a seguinte observação: a placa não está em qualquer lugar. Está na USP, lugar histórico, no qual passaram uma série de intelectuais e políticos de renome do cenário nacional, e que teve uma participação relevante no processo de redemocratização e de luta contra a Ditadura no país. Mais precisamente, está em um local de construção de um espaço destinado à memória e reflexão do período que o Brasil esteve imerso em um regime ditatorial. Espaço este que, por sua historicidade e atuação política contrária aos militares, vai na contramão do efeito de sentido que circula na placa, qual seja, o de que a tomada do poder pelos militares não foi uma revolução. Destacamos que o monumento se inscreve em uma perspectiva de identificação de preservação, em um ideal institucional, ligada, aquela que reverbera no ideal de arquivo, no qual nada falha e fura, no qual tudo (per)dura eternamente. Na placa, temos a materialização do jogo que envolve a memória e constitui o espaço discursivo do sujeito.

Fazer uso de uma palavra, e não de outras tantas, não é uma medida realizada de maneira aleatória ou solta. A questão da inscrição do sujeito na/pela escrita nunca é vazia. Somos afetados pela ideologia e pelo político. Como na "ditabranda" da Folha e nos implícitos que inscrevem denúncias do jornal Última Hora, a noção de esquecimento enunciativo é indispensável para que compreendamos a inevitável materialização da ideologia no discurso, seja no espaço da mídia impressa (atual ou não), seja nos dizeres oficiais do governo, mesmo décadas após o fim da ditadura. Invariavelmente, a mídia e a memória oficial vão instalar sentidos de combate ou relativização sobre o que representou a ditadura em nossa história, já que ao recorrer à linguagem para circular sentidos sobre o período vão, necessariamente, recortar da memória esta ou aquela palavra, que remete a uma FD em detrimento de outras.

Na placa, o uso do substantivo feminino "revolução" inscreve um espaço de dizer que é destoante do discurso dominante que circula acerca da tomada do poder pelos militares no ano de 1964. O uso da palavra "revolução" coloca em jogo toda uma memória discursiva acerca da questão, na qual se retoma um dizer que era oficial, no caso, um governo que apresentava-se como legitimo no período de sua existência, e que, na realização de seus atos, dizia-se dentro da legalidade e das normas aceitáveis por seus representantes. Temos novas representações desse período, no qual temos esse período histórico imerso em discursos que atestam as práticas de toda sorte de abusos de poder, que incluem sequestros, torturas, ocultamento de cadáveres, etc. Ou seja, o discurso da pretensa legalidade dos militares não é o dominante hoje, mas resiste. Não apenas no que é dito (como no caso da "ditabranda"), mas ainda no que é silenciado, no que a mídia e o governo consideram "irrelevantes" e não levam à discussão - o que inclui, por exemplo, investigação e julgamento de torturadores. 
Fazer uso da palavra "revolução" é se inscrever em uma FD na qual se compreende como legítima os anos de governo dos militares em nosso país. É inscrever esse período, não mais envolto em significantes de criminalidade ou ilegalidade. $O$ deslize, o uso de outra palavra, coloca em circulação uma leitura outra, na qual o uso de uma palavra legitimada anteriormente em documentos oficiais diversos, da cartilha didática, grande mídia, ofícios governamentais, etc., permite uma emergência de oficialidade, em um escrito que não está em qualquer panfleto ou placa, mas exatamente naquele destinado a trabalhar com o não esquecimento dos que foram silenciados e tragados por esse período histórico. Temos o furo, a fal(h)a que constitui e permite o paradoxo que é inerente a linguagem. A FD afeta a forma como o sujeito se inscreve no discurso, produz sentidos e é fator determinante para a ocorrência do(s) movimento(s) de tensão que envolve os sujeitos no discurso.

Na mesma placa, o discurso escrito e inscrito pelo oficial é silenciado. O que furou rompe em novo furo. Temos a emergência de outra(s) leitura(s). Retomamos o já-dito e reafirmamos: a mudança de uma palavra não é apenas a mudança de uma palavra. Temos questões do ideológico, político e do sentido em jogo. O substantivo feminino é sobrescrito, riscado, como se risca da carne a imperfeição, mas sem deixar que ela suma, pois ela constitui, o desejo que se veja que o antigo permanece, mas soterrado, (re)feito pelo novo. O apagamento não desfaz o que estava ali, mas abre para outra(s) leituras e sentido(s). Ao mesmo tempo em que se apaga, não se apaga. Como uma nova tatuagem, que não apaga ou destrói o desenho anterior, mas passa a integrá-lo, em uma constituição paradoxal. Na placa, o interesse não é apenas corrigir ou apagar, mas mostrar que a interdição ocorreu e integra o processo de existência da materialidade ali vigente.

Inscrever "golpe" é marcar uma posição no discurso. É o histórico e o ideológico fazendo-se presente no texto. Usar o substantivo "golpe" marca essa noção de que se trata não de um ato que ocorreu pelo desejo de uma maioria, mas pelas mãos de um grupo dominante, que obteve tal feito pela força, pela imposição. Essa noção é hoje a dominante nos espaços oficiais, os mesmos que anteriormente abrigavam outros discursos. Essa noção se filia a uma dada FD, na qual temos uma não concordância com o sentido ali apresentado e que se filia as noções de ilegalidade que marcam os governos militares no discurso contemporâneo. Enquanto a marca "revolução" concebe uma filiação a uma FD que considera a legalidade desses governos e suas ações. Várias (des)filiações se fazem possíveis, assim como existem várias FDs. Fica interessante ver isso na circulação do discurso observada nos comentários postados logo abaixo da reportagem eletrônica do jornal.

Dois fatos interessantes marcam o desfecho da polêmica placa. Segundo informações da Folha de S. Paulo ${ }^{9}$, a placa foi retirada algumas horas depois da reportagem, passando por críticas da ministra dos Direitos Humanos, Maria do Rosário Nunes, que coordena a Secretaria de Direitos Humanos, que qualificou como "absurdo" o uso da palavra "revolução". Interessante observar que a ministra se filia a uma FD outra, distinta dos dizeres impressos na placa e aprovados pela Secretaria que ela coordena. A ministra se filia em uma posição de discordância com o que foi posto em discurso, se ligando a sentidos apresentados na marca do grifo produzido. A retirada da placa marca

\footnotetext{
${ }^{9}$ Matéria do Jornal Folha de São Paulo de 04 de outubro de 2010, intitulada "Empresa retira placa na USP que chama golpe de 'revolução de 64"'. Disponível em http://www1.folha.uol.com.br/poder/985440empresa-retira-placa-na-usp-que-chama-golpe-de-revolucao-de-64.shtml; acesso em jan. 2014.
} 
um efeito de interdição, silenciamento, na busca de encerrar as polêmicas, colocando um fim a qualquer materialidade ali existente e que prove que o aquilo foi dito. Algo da ordem do ilusório, do inexistente, pois, mesmo não existindo mais (materialmente) outras formas de discursos, foram produzidos a partir daquele discurso, seja as materialidades imagéticas veiculadas por órgãos da grande mídia ou mesmo nas discussões que foram produtos dessa questão e que ocorreram pela Universidade, além de outras maneiras de circulação desses dizeres. Destacamos que a reportagem veiculada pela Folha de São Paulo não apresenta duas outras palavras que foram inscritas na placa: "ditadura" e "massacre" e que retomam o já-lá de um período marcado por um governo que praticou ilegalidades e não realizou ações em concordância ou respeito com os direitos democráticos, da mesma forma que não foi uma opção, mas uma imposição de pessoas que tomaram o poder a força. Observamos que de acordo com o blog Vi o mundo, essas inscrições foram inseridas posteriormente por outra aluna da USP. Reafirmamos que optamos por analisar o dizer "golpe", pois ele foi o que circulou com grande destaque pelo espaço midiático e das redes sociais brasileiras, como pode ser observado na reportagem da Folha de São Paulo ${ }^{10}$. No entanto, é interessante observar como a placa, que já havia posto em jogo novos discursos e sentidos, agrega outros tantos que caminham na oposição do que é legitimado pelo dizer oficial, agregando novas marcas ao seu corpo e ainda afirmamos que dependendo da posição discursiva e da FD que o sujeito se vincula outras tantas palavras caberiam naquele espaço.

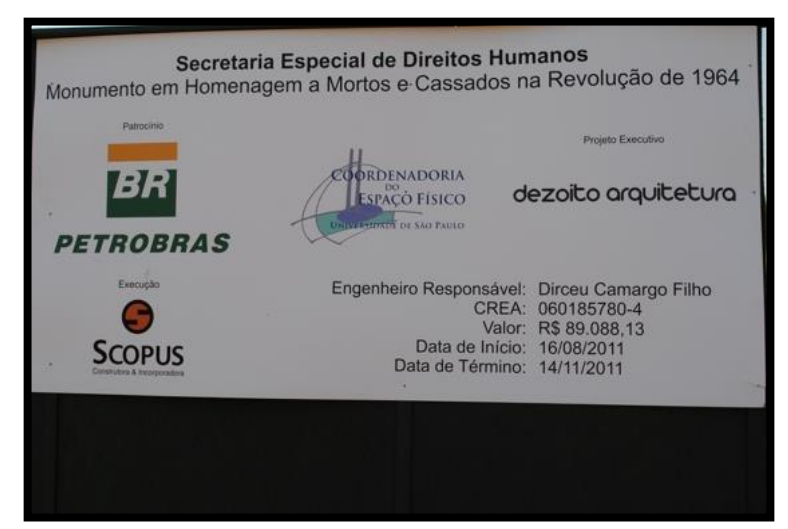

llustração 4 - Placa da USP: golpe ou revolução? ${ }^{11}$

\footnotetext{
${ }^{10}$ Matéria do Jornal Folha de São Paulo de 04 de outubro de 2010, intitulada "Placa na USP chama golpe militar de 'revolução de 1964"'. Disponível em http://www1.folha.uol.com.br/poder/985149-placa-na-uspchama-golpe-militar-de-revolucao-de-1964.shtml; acesso em jan. 2014.

${ }^{11}$ Fonte da imagem: Postagem do blog Vi o mundo: o que você não vê na política, de postagem do dia 04 de outubro de 2010, intitulada "Aluna da USP: Escrevi ditadura e massacre; placa me agrediu muito". Disponível em http://www.viomundo.com.br/denuncias/aluna-da-usp-escrevi-ditadura-e-massacre-placame-agrediu-profundamente.html; acesso em nov. 2014.
} 


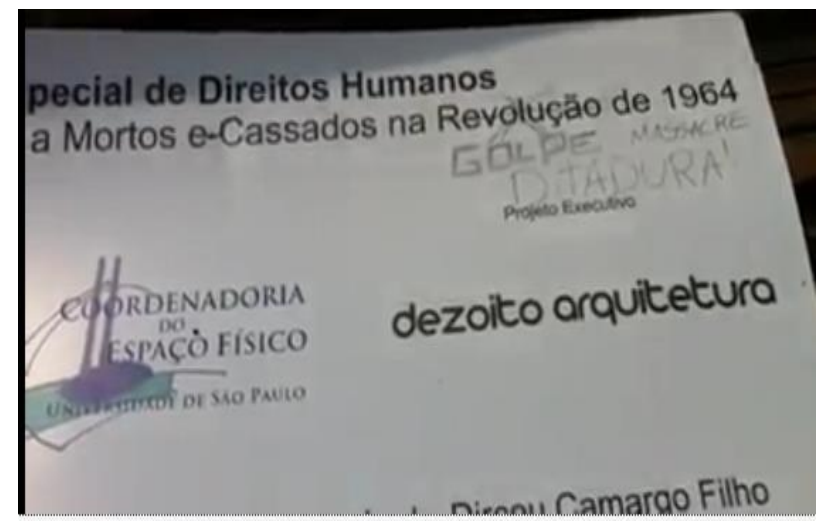

llustração 5 - Placa da USP: golpe ou revolução? ${ }^{12}$

A placa destruída foi interditada, em uma vã tentativa de que caia no esquecimento, de forma a ser silenciada na ordem do permanente. Na placa, temos o desejo do(s) silêncio(s). Silêncios e não silêncio, no singular, já que para a $\mathrm{AD}$, se as palavras são múltiplas, o silêncio também o é (ORLANDI, 1997). Marcamos na tentativa com a destruição da placa a ocorrência do silêncio local, no qual se deseja evitar a circulação de um dado dizer, temos o ato de censura, da mesma forma, temos o silêncio constitutivo marcamos que ao dizer "revolução" se deixa de dizer "golpe", é inerente, para dizer de uma forma, deixar de dizer de tantas outras maneiras (ORLANDI, 2008).

\section{Considerações Finais}

Nas análises que fizemos no transcorrer deste artigo, notamos a ambiguidade e politização inerentes ao discurso presentes em todos os recortes, inclusive nas marcas de implícitos e apagamentos que neles percebemos. Apesar disso, em todos os recortes notamos a pretensão de um mascaramento da filiação ideológica do discurso, filiação que é inevitável, mas negada por veículos midiáticos e registros do governo, que projetam seus dizeres como unívocos e fazem circular um aspecto de "neutralidade" no arquivo que chega a nós sobre a ditadura militar e como ela é denominada.

Essa suposta obviedade nas referências sobre a ditadura cai por terra pelas diversas denominações possíveis para o período político que o Brasil atravessou entre 1964 e 1985 : ditadura, regime, golpe, revolução, ditabranda etc. Em todos os casos, significantes que eivam retomadas a regiões de sentido e se alinham politicamente a determinada formação discursiva. Ao (se) inscrever (n)a linguagem, o sujeito invariavelmente fala afetado pela ideologia, mas se esquece disso ao enunciar, como lembra Pêcheux (1997).

Como a AD se pauta na multiplicidade de sentidos possíveis e rechaça qualquer simplismo conteudista no decorrer das análises, pudemos verificar como o sentido dominante mudou nas referências sobre a ditadura, porém em todos os casos o discurso

\footnotetext{
${ }^{12}$ Fonte da imagem: Postagem do blog Vi o mundo: o que você não vê na política, de postagem do dia 04 de outubro de 2010, intitulada "Aluna da USP: Escrevi ditadura e massacre; placa me agrediu muito". Disponível em http://www.viomundo.com.br/denuncias/aluna-da-usp-escrevi-ditadura-e-massacre-placame-agrediu-profundamente.html; acesso em nov. 2014.
} 
midiático e/ou governamental encontra resistências ao já-estabelecido mesmo nas FDs que mais se pautam no apagamento da historicidade. Isso acontece em todo caso, seja nas condições de produção em que o discurso de resistência instala denúncias contra os crimes dos militares, seja no discurso igualmente de resistência que, com a mudança do contexto sócio-histórico, busca relativizar as atrocidades cometidas pela "ditabranda". A nós, leitores e cidadãos para quem esse discurso é endereçado, cabe desnaturalizar esses enunciados e compreender sentidos para além do que nos projetam como óbvio e literal.

\section{Referências}

AUTHIER-REVUZ, J. Dialogismo e divulgação científica. Revista Rua, Campinas, n. 5, mar. 1999.

. Heterogeneidade(s) enunciativa(s). Caderno de Estudos Linguísticos, Campinas, v. 19, pp. 25-42, jul./dez. 1990. Disponível em http://revistas.iel.unicamp.br/index.php/cel/article/view/3012/4095; acesso em jun. 2014.

BARONAS, R. L. Ainda sobre a noção-conceito de formação discursiva em Pêcheux e em Foucault. Em: BARONAS, R. L. (Org.). Análise do Discurso: apontamentos para uma história da noção-conceito de formação discursiva. ${ }^{2}$. ed. São Carlos: Pedro \& João Editores, 2011. pp. 193-206.

Formação discursiva em Pêcheux e Foucault: uma estranha paternidade. Em: SARGENTINI, V. M. O.; NAVARRO-BARBOSA, P. (Orgs.). Foucault e os domínios da linguagem: discurso, poder e subjetividade. São Carlos: Claraluz, 2004.

FOLHA de S. Paulo. Castelo: repressão sem excessos. p. 01, 22 set. 1966. Disponível em http://acervo.folha.com.br/fsp/1966/09/22/2; acesso em out. 2014.

No Brasil não há ditadura: Castelo responde às críticas do Senado dos EUA. p. 01, 23 mai. 1966. Disponível em http://acervo.folha.com.br/fsp/1966/05/23/2; acesso em out. 2014.

INDURSKY, F. Da interpelação à falha no ritual: a trajetória teórica da noção de formação discursiva. Em: BARONAS, R. L. (Org.). Análise do Discurso: apontamentos para uma história da noção-conceito de formação discursiva. $2^{a}$. ed. São Carlos: Pedro \& João Editores, 2011. pp. 77-91.

INDURSKY, F. Formação discursiva: essa noção ainda merece que lutemos por ela? Em: INDURSKY, F.; FERREIRA, M. C. L. Análise do discurso no Brasil: mapeando conceitos, confrontando limites. São Carlos: Claraluz, 2007. pp. 163-172.

LAGAZZI-RODRIGUES, S.; BRITO, P. S. As ocupações dos sem-teto na discursividade da cidade. Em: ORLANDI, E. P. Cidade atravessada: os sentidos públicos no espaço. Campinas: Pontes, 2001. pp. 51-59. 
LAMPOGLIA, F. Discursividades da/sobre a ditadura militar em uma hemeroteca digital. Dissertação (Mestrado em Ciência, Tecnologia e Sociedade), Universidade Federal de São Carlos, São Carlos, 2012.

ORLANDI, E. P. Terra à vista - discurso do confronto: velho e novo mundo. $2^{\mathrm{a}}$. ed. Campinas: Editora da Unicamp, 2008.

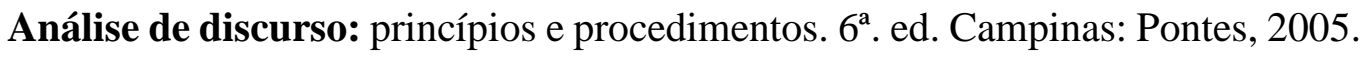

As formas do silêncio: no movimento dos sentidos. $4^{\mathrm{a}}$. ed. Campinas: Editora da Unicamp, 1997.

PÊCHEUX, M. Metáfora e interdiscurso. Em:

Análise de Discurso: Michel

Pêcheux. Textos escolhidos por Eni P. Orlandi. Campinas: Pontes, 2011. pp. 151-161.

. [1975]. Semântica e discurso: uma crítica à afirmação do óbvio. $3^{\mathrm{a}}$. ed. Trad.

Bras. Campinas: Editora da Unicamp, 1997.

PROPP, V. Comicidade e riso. São Paulo: Ática, 1992.

ROMÃO, Lucília Maria S. Mais de perto, mil faces secretas sob a face neutra: considerações sobre a heterogeneidade no discurso jornalístico. Revista Signótica, Goiânia, v. 17, n. 2, pp. 233-250. Disponível em http://www.revistas.ufg.br/index.php/sig/article/view/3729/3484; acesso em out. 2014.

Para citar este texto:

BASTOS, Gustavo Grandini; LAMPOGLIA, Francis; SILVA, Jonathan Raphael Bertassi da; ABRAHÃO E SOUSA, Lucília Maria. Golpe ou revolução? Um jogo discursivo na mídia. Entremeios [Revista de Estudos do Discurso], Seção Estudos, Programa de Pós-graduação em Ciências da Linguagem (PPGCL), Universidade do Vale do Sapucaí, Pouso Alegre (MG), vol. 12, p. 27-43, jan. - jun. 2016.

DOI: http://dx.doi.org/10.20337/ISSN2179-3514revistaENTREMEIOSvol12pagina27a43 